\title{
Safety and efficacy of infliximab in the treatment of refractory uveoretinitis in Behçet's disease: a large-scale, long-term postmarketing surveillance in Japan
}

\author{
Shigeaki Ohno ${ }^{1,2^{*}}$ (D) Itsuro Umebayashi ${ }^{3}$, Miyuki Matsukawa ${ }^{3}$, Takashi Goto ${ }^{3}$ and Toshiro Yano ${ }^{4}$
}

\begin{abstract}
Background: Infliximab, an anti-tumor necrosis factor-alpha antibody, has been reported to have excellent efficacy for refractory uveoretinitis in Behçet's disease (RUBD), and was approved for this indication in Japan. However, the long-term safety profile and efficacy in real-world clinical settings in patients with RUBD have not been fully clarified. The BRIGHT study, a prospective, large-scale, long-term postmarketing surveillance (PMS) study, was conducted to investigate the long-term safety and efficacy of infliximab in Japanese patients with RUBD.
\end{abstract}

Methods: All patients with RUBD who started infliximab treatment between January 2007 and January 2010 were enrolled. Safety was evaluated every 6 months for up to 24 months after initiation of therapy in 656 patients, and efficacy was evaluated in 650 patients. Patient characteristics were compared using the chi-square or Fisher's exact test. The frequency of ocular attacks before and after infliximab treatment was compared using the Wilcoxon signed-rank test. Independent associated factors for safety or efficacy were identified using multiple logistic regression analysis. A two-sided $p$ value $<0.05$ was considered significant.

Results: Among the 656 patients evaluated for safety, 555 (84.6\%) completed the 24-month study period. The incidence of adverse drug reactions (ADRs) and serious ADRs were $32.32 \%$ and $6.10 \%$, respectively, and the safety profile was comparable to that of Japanese PMS of infliximab for other diseases. The most common ADRs and serious ADRs were infections (11.89\% and 3.66\%). Tuberculosis was reported in two patients, and Pneumocystis jirovecii in one. Identified independent associated factors for infections were comorbid respiratory disease, history of allergic disease, and concomitant use of glucocorticoids. Although infusion reactions were observed in $11.13 \%$ of patients, most were non-serious. The response rate at 24 months by physician global assessment was $80.7 \%$. Median frequency of ocular attacks per 6 months significantly decreased compared with that before infliximab treatment (2.0 to 0.0), and corrected visual acuity was maintained during the study.

Conclusions: Infliximab treatment had good tolerability and efficacy in Japanese patients with RUBD in this large-scale, long-term PMS. Infliximab treatment seemed to be a good treatment option for RUBD in real-world clinical settings.

Trial registration: UMIN Clinical Trials Registry, UMIN000027733. Retrospectively registered on 6 June 2017.

Keywords: Behçet's disease, Uveoretinitis, Biological therapies, Infliximab, Postmarketing surveillance, Safety, Efficacy, Associated factor

\footnotetext{
* Correspondence: sohno@med.hokudai.ac.jp

${ }^{1}$ Department of Ophthalmology, Faculty of Medicine and Graduate School of

Medicine, Hokkaido University, N 15, W 7, Kita-ku, Sapporo, Hokkaido

060-8638, Japan

2Department of Ophthalmology, Aishin Memorial Hospital, 1-15, N27, E1,

Higashi-ku, Sapporo, Hokkaido 065-0027, Japan

Full list of author information is available at the end of the article
}

(c) The Author(s). 2019 Open Access This article is distributed under the terms of the Creative Commons Attribution 4.0 International License (http://creativecommons.org/licenses/by/4.0/), which permits unrestricted use, distribution, and reproduction in any medium, provided you give appropriate credit to the original author(s) and the source, provide a link to the Creative Commons license, and indicate if changes were made. The Creative Commons Public Domain Dedication waiver (http://creativecommons.org/publicdomain/zero/1.0/) applies to the data made available in this article, unless otherwise stated. 


\section{Background}

Behçet's disease (BD), common along the coast of the Mediterranean Sea and the Silk Road extending to Japan, is a systemic inflammatory condition of unknown etiology characterized by recurrent aphthous ulcers, skin lesions, genital ulcers and ocular lesions [1]. Ocular inflammation in BD causes uveoretinitis, which in severe cases results in irreversible damage to the retina and optic nerve, and blindness. Current treatments for BD uveoretinitis include glucocorticoids, cyclosporine and other immunosuppressants. In particular, cyclosporine exerts potent immunosuppressive activity via the suppression of T-cell function, and various guidelines recommend its use for the treatment of BD uveoretinitis [2]. However, given the adverse drug reactions (ADRs) associated with cyclosporine, including nephrotoxicity and central nervous system effects, and the existence of non-responders to cyclosporine, a novel therapeutic agent is desirable.

Tumor necrosis factor-alpha (TNF) has been implicated in the pathogenesis of BD. TNF mediates murine susceptibility to experimental autoimmune uveoretinitis (EAU) [3], while administration of anti-TNF antibodies effectively suppresses the induction of EAU [4]. Further, monocyte-derived TNF levels are elevated in patients with ocular symptoms of BD [5].

Infliximab (IFX), an anti-human TNF monoclonal antibody, neutralizes TNF activity and binds to transmembrane TNF-producing cells, resulting in their apoptosis [6, 7]. IFX has shown good efficacy against various inflammatory diseases, including inflammatory bowel disease, rheumatoid arthritis (RA), and psoriasis [8-15], and has been administered to close to 3 million patients with these diseases. In addition, it has also been reported to be useful in patients with refractory uveoretinitis of BD (RUBD) [15-17]. Based on findings of early phase II clinical trials $(n=13)$ [18], long-term trials $(n=9)$, and phase III trials $(n=12)$ in Japanese patients with RUBD (Mitsubishi Tanabe Pharma Corporation internal data), IFX was approved for this indication in Japan for the first time in the world in January 2007.

Here, to investigate the safety and efficacy of IFX treatment in RUBD in clinical practice, we conducted a prospective, large-scale, long-term postmarketing surveillance (PMS) study of all IFX-treated patients in Japan (the BRIGHT study: PMS in patients with Behcet's disease at Remicade (Infliximab) treatment; lonG-term safety/efficacy for sigHT-threating uveoretinitis).

\section{Methods}

\section{Study design and patients}

This PMS study (UMIN000027733) included all patients with RUBD starting treatment with IFX at 215 Japanese medical institutions between January 2007 and January
2010. These patients had not responded to conventional therapy, including glucocorticoids, cyclosporine, colchicine (which is often used and recommended for treatment of RUBD in Japan) [19, 20]. and other immunosuppressants. The evaluation period was 24 months in total, and safety and efficacy data were prospectively collected at the end of 6,12 , and 24 months during the evaluation period.

\section{Procedures}

Prior to initiating IFX, patients were examined for the presence of tuberculosis (TB) by inquiring about past medical and family history, and tuberculin skin tests (TST) and radiographic chest examinations. Anti-TB agents were administered in suspected cases of TB infection.

Patients received commercially available IFX (Remicade $^{\oplus}$ ) at $5 \mathrm{mg} / \mathrm{kg}$ body weight at weeks 0,2 , and 6 , and then every 8 weeks thereafter (in accordance with the indication for RUBD in Japan) for the entire 24 months of the study. Information on ADRs were recorded, including type, date of diagnosis, severity, and outcome, and ADRs were classified according to the preferred terms and system organs class (SOC) of the Medical dictionary for regulatory activities (MedDRA/J, version 19.1, http:// www.meddra.org/sites/default/files/guidance/file/intguide_19_1_japanese.pdf, Japanese article, last accessed December 25, 2018). Infusion reactions (IRs) were defined as any ADRs occurring during or within $2 \mathrm{~h}$ after the completion of any infusion.

The clinical response was evaluated based on physician global assessment (PGA) using a 4-point scale (improved, slightly improved, unchanged, and worsened). PGA was used for analysis of clinical response as most patients enrolled in this study were anticipated to have severe symptoms prior to this study, resulting in inaccurate evaluation by using ocular severity (severe/ moderate/mild). PGA was evaluated by each physician by comparing the ocular symptoms before and at 3-month intervals during IFX treatment, with "improved", or "slightly improved" defined as the patient having a PGA response.

The number of ocular attacks was evaluated every 6 months in patients in whom ocular attacks within 6 months prior to initiation of IFX were evaluated. To precisely evaluate efficacy in reducing ocular attacks and associated factors, we evaluated efficacy in patients who had no history of IFX treatment and had at least one episode of ocular attack within 6 months prior to IFX treatment. Corrected visual acuity was examined on a monthly basis. Final efficacy (at 24 months) was evaluated using both as-observed and last observation carried forward (LOCF) analysis.

In addition, changes in the dose of concomitant cyclosporine, glucocorticoids, and colchicine, and the percentage of patients receiving these agents were examined. 


\section{Statistical analysis}

Continuous data were summarized using descriptive statistics. Discrete data were summarized based on the number and percentage values for each category. Patient characteristics were compared using the chi-square test or Fisher's exact test. The frequency of ocular attacks within 6 months before and after IFX treatment was compared using the Wilcoxon signed-rank test. Independent correlations among factors associated with the development of any infections, or response in PGA (improved or slightly improved), were identified using multiple logistic regression analysis. Multiple logistic regression analysis of the absence of ocular attacks after the initiation of IFX treatment included the number of ocular attacks in the 6 months prior to IFX treatment as an explanatory variable. All multiple logistic regression analyses were conducted using a stepwise selection process. A significance level of 5\% and two-sided 95\% confidence intervals (CIs) were defined. Statistical analyses were performed using SAS software version 9.1.3 (SAS Institute Japan Ltd., Tokyo, Japan).

\section{Results}

\section{Patients}

In total, 667 patients in whom IFX treatment was initiated were enrolled in this study, and case report data were obtained for 663 patients. Of these 663 patients, 7 were excluded due to various reasons such as failure to meet the inclusion criteria $(n=5)$ or hospital transfer $(n$ $=2$ ), leaving 656 patients who could be evaluated for safety. Efficacy was evaluated in 650 patients for whom efficacy data were available (Fig. 1).

The demographics and disease characteristics of patients who participated in this study are shown in Table 1. With regard to 656 patients monitored for drug safety, $23.5 \%$ were female, mean age was 40.1 years, with respective mean disease durations of $\mathrm{BD}$ and uveoretinitis of 7.46 and 6.63 years, respectively.

Many patients had severe uveoretinitis (62.2\%). The majority had extraocular involvement $(90.2 \%)$, the most common of which was recurrent oral aphthous ulcers (81.4\%), followed by skin lesions (59.8\%) and genital ulcers (34.5\%). Cyclosporine, glucocorticoids, and colchicine were used in $38.3 \%, 36.4 \%$, and $50.0 \%$ of patients, respectively, within 6 months prior to IFX treatment. Median (1st quartile (Q1), 3rd quartile (Q3)) IFX dosage was $5.00(5.00,5.00) \mathrm{mg} / \mathrm{kg}$ body weight, and the rates of $<5.00 \mathrm{mg} / \mathrm{kg}, 5.00 \mathrm{mg} / \mathrm{kg}$, and $>5.00 \mathrm{mg} / \mathrm{kg}$ were $5.9 \%$, $85.2 \%$, and $8.8 \%$, respectively.

The number of patients followed for 6,12 , and 18 months were 624,597 , and 565 , respectively, and 555 patients completed the study period. The main reasons for discontinuation were transfer/failure to attend hospital $(n=56)$, followed by the occurrence of adverse events $(n=28)$. Mean (SD) length of observation was 666.9 (172.1) days, and median (Q1, Q3) number of IFX administrations was $15.0(14.0,15.0)$ times.

\section{Safety}

ADRs and serious ADRs were observed in 32.32\% (212/ $656)$ and $6.10 \%(40 / 656)$ of patients, respectively, during the study period (day 0-730, Table 2). Occurrence of ADRs tended to be higher at the initiation of treatment, and no increase was observed thereafter. The incidence of all ADRs and serious ADRs classified using the MedDRA/ J SOC are also described in Table 2. "Infections and infestations" was the most common ADR (11.89\%), followed by "skin and subcutaneous tissue disorders" (9.60\%). The most common serious ADRs were also Infections and infestations (3.66\%), while the occurrences of other serious ADRs $<1.0 \%$. Major infections were nasopharyngitis $(n=$ $10)$, gastroenteritis $(n=7)$, herpes zoster, pharyngitis, and pneumonia (each $n=6$ ); and major serious infections were

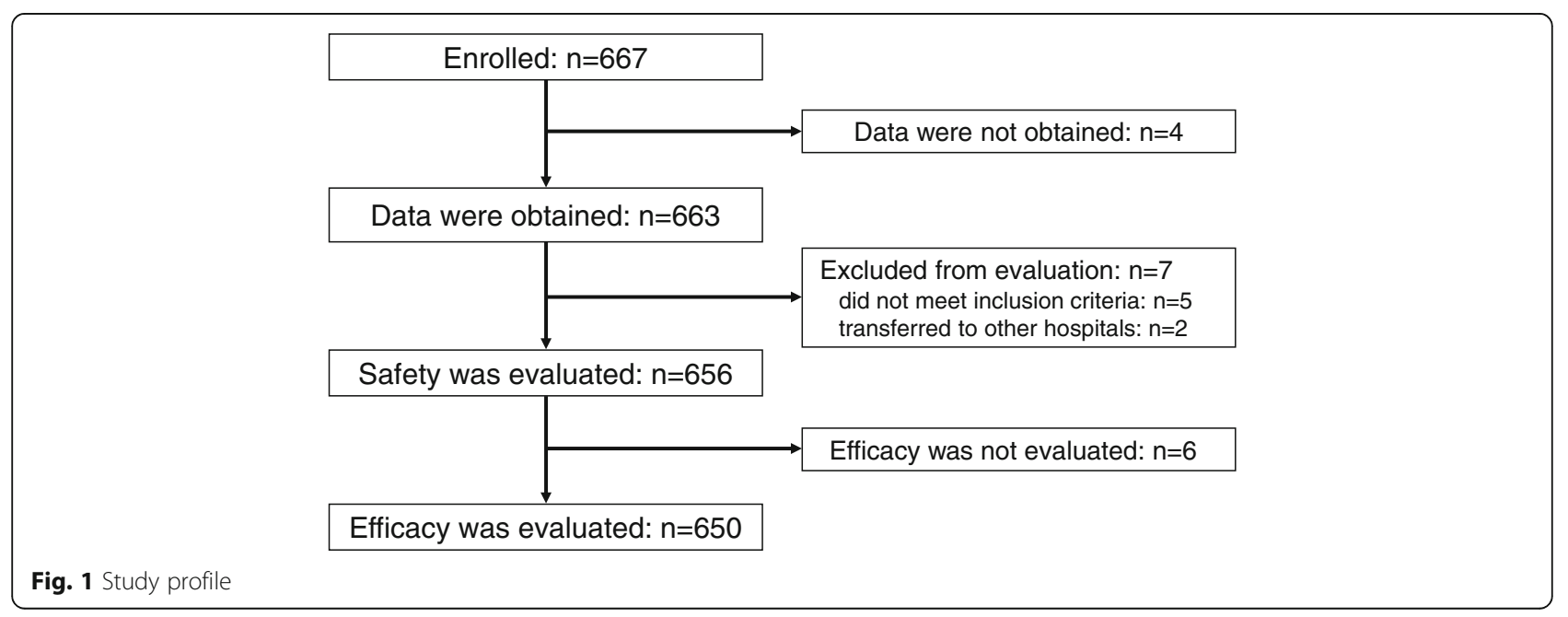


Table 1 Patient characteristics

\begin{tabular}{|c|c|}
\hline & $\begin{array}{l}\text { Value in patients }(n= \\
656)\end{array}$ \\
\hline Sex (female) & $154(23.5)$ \\
\hline \multicolumn{2}{|l|}{ Age, years } \\
\hline mean (SD), [range] & $40.1(12.1),[10-78]$ \\
\hline$<15$ & $3(0.5)$ \\
\hline$\geq 15-<25$ & $46(7.0)$ \\
\hline$\geq 25-<35$ & $189(28.8)$ \\
\hline$\geq 35-<45$ & $219(33.4)$ \\
\hline$\geq 45-<55$ & $109(16.6)$ \\
\hline$\geq 55-<65$ & $65(9.9)$ \\
\hline$\geq 65$ & $25(3.8)$ \\
\hline \multicolumn{2}{|l|}{ Disease duration of $\mathrm{BD}$, years } \\
\hline mean (SD), [range] & $7.46(6.80),[0.1-49.0]$ \\
\hline$<5$ & $268(40.9)$ \\
\hline$\geq 5-<10$ & $159(24.2)$ \\
\hline$\geq 10-<15$ & $95(14.5)$ \\
\hline$\geq 15$ & $77(11.7)$ \\
\hline unknown & $57(8.7)$ \\
\hline \multicolumn{2}{|l|}{ Disease duration of uveitis, years } \\
\hline mean (SD), [range] & $6.63(5.91),[0.0-36.0]$ \\
\hline$<5$ & $294(44.8)$ \\
\hline$\geq 5-<10$ & $166(25.3)$ \\
\hline$\geq 10-<15$ & $86(13.1)$ \\
\hline$\geq 15$ & $60(9.1)$ \\
\hline unknown & $50(7.6)$ \\
\hline \multicolumn{2}{|l|}{ Severity of ocular symptoms } \\
\hline severe & $408(62.2)$ \\
\hline moderate & $201(30.6)$ \\
\hline mild & $36(5.5)$ \\
\hline unknown & $11(1.7)$ \\
\hline History of TB infection & $35(5.3)$ \\
\hline Prophylactic anti-TB drug & $242(36.9)$ \\
\hline History of HBV infection & $6(0.9)$ \\
\hline unknown & $1(0.2)$ \\
\hline History of allergic disease & $38(5.8)$ \\
\hline History of IFX use & $31(4.7)$ \\
\hline \multicolumn{2}{|l|}{ Extraocular symptoms of BD } \\
\hline any symptoms & $592(90.2)$ \\
\hline oral aphthous ulcers & $534(81.4)$ \\
\hline genital ulcers & $226(34.5)$ \\
\hline skin lesions & $392(59.8)$ \\
\hline arthritis & $171(26.1)$ \\
\hline epididymitis & $30(4.6)$ \\
\hline central nervous system lesions & $64(9.8)$ \\
\hline
\end{tabular}

Table 1 Patient characteristics (Continued)

\begin{tabular}{|c|c|}
\hline & $\begin{array}{l}\text { Value in patients }(n= \\
656)\end{array}$ \\
\hline intestinal tract lesions & $67(10.2)$ \\
\hline vascular lesions & $20(3.0)$ \\
\hline other symptoms & $26(4.0)$ \\
\hline unknown & $5(0.8)$ \\
\hline \multicolumn{2}{|l|}{ Comorbidity } \\
\hline any comorbidity & $360(54.9)$ \\
\hline respiratory disease & $10(1.5)$ \\
\hline hepatic disease & $35(5.3)$ \\
\hline cardiac disease & $10(1.5)$ \\
\hline ocular disease & $185(28.2)$ \\
\hline kidney disease & $23(3.5)$ \\
\hline malignancy & $2(0.3)$ \\
\hline diabetes mellitus & $31(4.7)$ \\
\hline other diseases & $200(30.5)$ \\
\hline \multicolumn{2}{|l|}{ Drug use in prior 6 months } \\
\hline cyclosporine & $251(38.3)$ \\
\hline dose, median (Q1, Q3), mg/day, $n=242^{\mathrm{a}}$ & $168.24(120.00,200.00)$ \\
\hline glucocorticoids & $239(36.4)$ \\
\hline dose, median (Q1, Q3), mg/day, $n=235^{\mathrm{a}}$ & $13.07(7.50,20.00)$ \\
\hline colchicine & $328(50.0)$ \\
\hline dose, median (Q1, Q3), mg/day, $n=325^{\mathrm{a}}$ & $1.00(1.00,1.00)$ \\
\hline $\begin{array}{l}\text { Infliximab dose, median (Q1, Q3) [range], mg/ } \\
\text { kg }\end{array}$ & $5.00(5.00,5.00)[3.4-6.4]$ \\
\hline
\end{tabular}

pneumonia $(n=4)$, cellulitis, gastroenteritis, septic shock, and sinusitis (each $n=2$ ).

Tuberculosis (TB) was observed in two patients $(0.30 \%)$ who had not received anti-TB therapy despite a positive tuberculin skin test (TST) (diameter $\geq 10 \mathrm{~mm}$ ); one had pulmonary TB and intrathoracic lymph node involvement and the second had disseminated TB. Both cases resolved after anti-TB treatment. No TB case was observed in patients who received prophylactic anti-TB drugs. Opportunistic infections were observed in three patients, including cytomegalovirus infection, septic shock, and pneumocystis pneumonia (each $n=1$ ). All cases resolved after anti-viral, anti-microbial, or anti-fungal treatment.

Infusion reactions (IRs) and serious IRs were observed in $73(11.13 \%)$ and $3(0.46 \%)$ of patients, respectively (Additional file 1: Figure S1). IRs occurred from the 1st to the 16 th infusion at a rate of $0.37-2.15 \%$ for each infusion, with no tendency towards more IRs at an earlier stage of treatment. Serious IRs (three patients, five incidences) were observed on the 4th, 5th, 8th, 9th, and 14th 
Table 2 Safety profile of infliximab therapy classified by system organ class (SOC)

\begin{tabular}{|c|c|c|c|c|c|}
\hline & $\begin{array}{l}\text { Day 0-180 } \\
(n=656)\end{array}$ & $\begin{array}{l}\text { Day 181-365 } \\
(n=624)\end{array}$ & $\begin{array}{l}\text { Day 366-545 } \\
(n=597)\end{array}$ & $\begin{array}{l}\text { Day 546-730 } \\
(n=565)\end{array}$ & $\begin{array}{l}\text { All period (day 0-730) } \\
(n=656)^{*}\end{array}$ \\
\hline Any ADRs & $122(18.60)$ & $73(11.70)$ & $44(7.37)$ & $40(7.08)$ & $212(32.32)$ \\
\hline Blood and lymphatic system disorders & 0 & 0 & $1(0.17)$ & 0 & $1(0.15)$ \\
\hline Cardiac disorders & $2(0.30)$ & $1(0.16)$ & 0 & 0 & $3(0.46)$ \\
\hline Eye disorders & $3(0.46)$ & $2(0.32)$ & $1(0.17)$ & 0 & $6(0.91)$ \\
\hline Gastrointestinal disorders & $8(1.22)$ & $2(0.32)$ & $1(0.17)$ & $1(0.18)$ & $12(1.83)$ \\
\hline General disorders and administration site conditions & $15(2.29)$ & $7(1.12)$ & $4(0.67)$ & $5(0.88)$ & $31(4.73)$ \\
\hline Hepatobiliary disorders & $4(0.61)$ & $1(0.16)$ & 0 & $1(0.18)$ & $5(0.76)$ \\
\hline Immune system disorders & $2(0.30)$ & 0 & $1(0.17)$ & 0 & $3(0.46)$ \\
\hline Infections and infestations & $35(5.34)$ & $25(4.01)$ & $14(2.35)$ & $13(2.30)$ & $78(11.89)$ \\
\hline Injury, poisoning and procedural complications & $7(1.07)$ & $5(0.80)$ & $6(1.01)$ & $5(0.88)$ & $19(2.90)$ \\
\hline Investigations & $18(2.74)$ & $5(0.80)$ & $3(0.50)$ & $5(0.88)$ & $30(4.57)$ \\
\hline Metabolism and nutrition disorders & $1(0.15)$ & 0 & $1(0.17)$ & 0 & $2(0.30)$ \\
\hline Musculoskeletal and connective tissue disorders & $3(0.46)$ & $3(0.48)$ & $2(0.34)$ & $1(0.18)$ & $8(1.22)$ \\
\hline Neoplasms benign, malignant and unspecified & $1(0.15)$ & 0 & $1(0.17)$ & $1(0.18)$ & $3(0.46)$ \\
\hline Nervous system disorders & $7(1.07)$ & $1(0.16)$ & $1(0.17)$ & 0 & $9(1.37)$ \\
\hline Respiratory, thoracic and mediastinal disorders & $12(1.83)$ & $13(2.08)$ & $5(0.84)$ & $5(0.88)$ & $29(4.42)$ \\
\hline Skin and subcutaneous tissue disorders & $39(5.95)$ & $20(3.21)$ & $16(2.68)$ & $7(1.24)$ & $63(9.60)$ \\
\hline Serious ADRs & $19(2.90)$ & $8(1.28)$ & $6(1.01)$ & $8(1.42)$ & $40(6.10)$ \\
\hline Blood and lymphatic system disorders & 0 & 0 & 0 & 0 & 0 \\
\hline Cardiac disorders & $1(0.15)$ & 0 & 0 & 0 & $1(0.15)$ \\
\hline Eye disorders & $1(0.15)$ & $1(0.16)$ & 0 & 0 & $2(0.30)$ \\
\hline Gastrointestinal disorders & $1(0.15)$ & 0 & 0 & 0 & $1(0.15)$ \\
\hline General disorders and administration site conditions & 0 & 0 & $1(0.17)$ & $1(0.18)$ & $2(0.30)$ \\
\hline Hepatobiliary disorders & 0 & 0 & 0 & 0 & 0 \\
\hline Immune system disorders & 0 & 0 & $1(0.17)$ & 0 & $1(0.15)$ \\
\hline Infections and infestations & $11(1.68)$ & $7(1.12)$ & $2(0.34)$ & $5(0.88)$ & $24(3.66)$ \\
\hline Injury, poisoning, and procedural complications & $1(0.15)$ & 0 & 0 & 0 & $1(0.15)$ \\
\hline Investigations & 0 & 0 & 0 & $1(0.18)$ & $1(0.15)$ \\
\hline Metabolism and nutrition disorders & 0 & 0 & 0 & 0 & 0 \\
\hline Musculoskeletal and connective tissue disorders & 0 & 0 & $1(0.17)$ & 0 & $1(0.15)$ \\
\hline Neoplasms benign, malignant and unspecified & $1(0.15)$ & 0 & 0 & $1(0.18)$ & $2(0.30)$ \\
\hline Nervous system disorders & $1(0.15)$ & 0 & $1(0.17)$ & 0 & $2(0.30)$ \\
\hline Respiratory, thoracic and mediastinal disorders & $3(0.46)$ & 0 & $1(0.17)$ & 0 & $4(0.61)$ \\
\hline Skin and subcutaneous tissue disorders & $1(0.15)$ & 0 & 0 & 0 & $1(0.15)$ \\
\hline
\end{tabular}

Data are number (percentage)

ADRs, adverse drug reactions

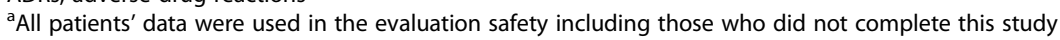

infusions. Among 71 patients who developed non-serious IRs, 66 (93.0\%) received re-infusion of IFX, among whom 1 subsequently developed a serious IR, 21 developed non-serious IRs, and 44 did not develop IRs. Both patients who developed serious IRs received re-infusion; one again developed a serious IR, while the second did not develop IRs thereafter (Additional file 1: Figure S1).
Lupus-like syndrome was observed in one patient who had an increase in anti-nuclear antibody but no symptoms. Demyelinating disorder was observed in one patient, and malignancies were observed in two (lung neoplasm and papillary thyroid cancer); their symptoms were resolved after the appropriate treatment. No fatal ADRs was observed during the study. 


\section{Efficacy}

Efficacy was evaluated in 650 patients (Fig. 1). Although PGA data were obtained for 642 patients, data were "undeterminable" in 19 patients. Therefore, PGA data were evaluated for the remaining 623 patients. The final response rate in PGA (LOCF) was 80.7\% (improved, 60.7\%; slightly improved, $20.1 \%$ ), and the response rates were sustained from 3 months $(82.1 \%)$ to up to 24 months in more than $80 \%$ (Table 4). Similar results were observed among 489 patients who had no history of IFX treatment and at least one ocular attack in the 6 months preceding IFX treatment, with response rates at 3-24 months of $83.1-90.6 \%$ (data not shown).

Efficacy in reducing ocular attacks was evaluated in 620 patients of whom 506 had at least one episode of ocular attack in the 6 months preceding IFX therapy and had no history of IFX use. Among these 506 patients, the median number of attacks was 2.0 during the 6 months before initiation of IFX (at 0 months). This improved significantly to 0.0 during the first 6 months post dosing (at 6 months, $p<0.001$ ), and the proportion of patients experiencing ocular attacks during the 6-month post-dose period decreased from 100\% to 30.5\% (Table 3). These figures remained almost constant throughout the study period, with 217 patients (42.9\%) experiencing no ocular attacks during the 24-month study period. Similar results were obtained on analysis of all patients who underwent evaluation of the number of ocular attacks during the 6 months before IFX $(n=$ $620)$; in these patients also, the number of ocular attacks decreased significantly.

Best-corrected visual acuity in 581 patients before and during IFX therapy is shown in Fig. 2a. Median best-corrected visual acuity before IFX treatment was $0.7-0.8$ and was $0.9-1.0$ at $9-24$ months, showing the maintenance of corrected visual acuity levels. Results were similar for analysis in each eye (left, $n=548$; right, $n=549$ ) (Fig. 2b).

\section{Reduction in concomitant drugs}

Table 4 shows the patient rate and dose of concomitant use of cyclosporine, oral glucocorticoids, and colchicine during this study. Although marked dose reductions in these drugs were not observed, usage rates gradually decreased during the study.

\section{Associated factors for safety and efficacy}

To investigate background factors that may influence the incidence of infections and efficacy, univariate analysis was first performed to check for correlations with various factors. Independent associated factors were then identified using multivariate logistic regression analysis.

Analysis of associated factors in infections was performed in all 656 patients included in the safety assessment. Table 5 shows the results of univariate analysis of patient background factors related to safety and efficacy (PGA response or absence of ocular attacks). Univariate analysis revealed that patients with a history of allergic disease or comorbid respiratory disease had a significantly higher incidence of infections (Table 5). In addition to these two factors, multivariate analysis also identified concomitant glucocorticoids as an independent associated factor.

Meanwhile, age was not significantly associated with infections or serious infections (data not shown), and no difference was observed in the incidence of infections and serious infections between elderly ( $\geq 65$ years, $n=$ 25) $(16.00 \%, 4.00 \%)$ and non-elderly subjects $(<65$ years, $n=631)(11.73 \%, 3.65 \%$, respectively). Moreover, incidence of infections showed no significant increase in patients receiving concomitant cyclosporine.

Disease duration, severity of ocular symptoms, and comorbid diabetes mellitus were significantly associated with both PGA response and the absence of ocular attacks. The efficacy of IFX was significantly lower in patients with longer disease duration and those with comorbid diabetes mellitus. Meanwhile, in patients with severe ocular symptoms, efficacy was higher than those in patients with moderate/mild symptoms $(83.6 \%$ versus $77.4 \%$ ) in terms of PGA response, but lower in terms of absence of ocular attacks (37.7\% versus $52.4 \%)$. In addition, while some extraocular symptoms (oral aphthous ulcers, skin lesions, central nervous system lesions, and intestinal tract lesions) were significantly associated with PGA responses, no extraocular symptoms were significantly associated with occurrence of ocular attacks. The results of multivariate analysis are shown in Additional file 1: Table S1. Some extraocular symptoms (oral aphthous ulcers, central nervous system lesions, and intestinal tract lesions) and some comorbidities (cardiac diseases and diabetes mellitus) were identified as associated factors for PGA response, whereas ocular symptom severity, number of ocular attacks during the 6 months preceding IFX treatment, and other factors were identified as independent associated factors related to the absence of ocular attacks.

\section{Discussion}

The number of patients with BD in Japan is estimated to be approximately 20,000 (number of persons with specific (intractable) disease healthcare certificates by disease and sex: http://www.mhlw.go.jp/english/database/ db-hh/xls/2-22.xls, last accessed December 25, 2018), $60 \%$ of whom have pre-existing ocular lesions. Further, $10 \%$ of these patients are unresponsive to conventional therapy [20].

Japan is the first country in the world to approve IFX for clinical use against RUBD (https://www.mt-pharma.co.jp/e/ 
Table 3 Efficacy of infliximab in ocular symptoms of Behçet's disease

\begin{tabular}{|c|c|c|c|c|c|c|}
\hline & At $0 \mathrm{M}$ & At $6 \mathrm{M}$ & At $12 \mathrm{M}$ & At $18 \mathrm{M}$ & At $24 \mathrm{M}$ & At $24 \mathrm{M}$ (LOCF) \\
\hline \multicolumn{7}{|l|}{ Physician global assessment (PGA) } \\
\hline Number of evaluated patients ${ }^{a}$ & - & $n=582$ & $n=557$ & $n=485$ & $n=465$ & $n=623$ \\
\hline Improved & - & $359(61.7)$ & $356(63.9)$ & $309(63.7)$ & $294(63.2)$ & $378(60.7)$ \\
\hline Slightly improved & - & $127(21.8)$ & $108(19.4)$ & $93(19.2)$ & $95(20.4)$ & $125(20.1)$ \\
\hline Unchanged & - & $87(14.9)$ & $84(15.1)$ & $70(14.4)$ & $67(14.4)$ & $105(16.9)$ \\
\hline Worsened & - & $9(1.5)$ & $9(1.6)$ & $13(2.7)$ & $9(1.9)$ & $15(2.4)$ \\
\hline \multicolumn{7}{|l|}{ Ocular attacks } \\
\hline Number of evaluated patients ${ }^{b}$ & $n=620$ & $n=613$ & $n=578$ & $n=540$ & $n=540$ & $n=620$ \\
\hline number of ocular attacks per $6 \mathrm{M}$ & $2.0(1.0,4.0)$ & $0.0(0.0,1.0)$ & $0.0(0.0,1.0)$ & $0.0(0.0,1.0)$ & $0.0(0.0,0.0)$ & $0.0(0.0,1.0)^{d}$ \\
\hline rate of patients with ocular attack per $6 \mathrm{M}$ & $542(87.4)$ & $168(27.4)$ & $184(31.8)$ & $144(26.7)$ & $132(24.4)$ & $157(25.3)^{d}$ \\
\hline Number of evaluated patients ${ }^{c}$ & $n=506$ & $n=502$ & $n=479$ & $n=448$ & $n=448$ & $n=506$ \\
\hline number of ocular attacks per $6 \mathrm{M}$ & $2.0(2.0,4.0)$ & $0.0(0.0,1.0)$ & $0.0(0.0,1.0)$ & $0.0(0.0,1.0)$ & $0.0(0.0,1.0)$ & $0.0(0.0,1.0)^{d}$ \\
\hline rate of patients with ocular attack per $6 \mathrm{M}$ & $506(100.0)$ & $153(30.5)$ & $169(35.3)$ & $135(30.1)$ & $123(27.5)$ & $146(28.9)^{d}$ \\
\hline
\end{tabular}

Data are number (percentage, or median (1st quartile, 3rd quartile). Efficacy data at 0 months (M) to $24 \mathrm{M}$ were analyzed as-observed, and those at $24 \mathrm{M}$ (last observation carried forward (LOCF)) were analyzed using the LOCF method

aEvaluated in 623 patients in whom PGA data were available excluding "underminable"

${ }^{b}$ Evaluated in 620 patients in whom number of ocular attacks within 6 months prior to infliximab treatment were evaluated

'Evaluated in 506 patients with at least one episode of ocular attacks in the prior 6 months and no history of infliximab treatment

${ }^{\mathrm{d}}$ Ocular attacks for 6 months during last observation period

release/nr/tanabe/2007/pdf/20070126e.pdf, last accessed December 25, 2018), and the efficacy and safety of this therapy have been previously demonstrated in patients with RUBD in Japan and in other countries [21-30]. However, the sample sizes in these studies were relatively limited, and factors associated with safety and efficacy were not fully clarified. Accordingly, the present study adds to the literatures [21-30] by documenting the safety and efficacy profile of IFX in 656 (650) patients with RUBD, a large population, over an extended time period.

The incidence of any ADR and serious ADRs during the first 6 months $(18.60 \%$ and $2.90 \%)$ were not higher than those in 6-month Japanese PMS studies in patients with rheumatoid arthritis $(28.02 \%$ and $6.16 \%)$ and psoriasis $(22.51 \%$ and $6.94 \%$, respectively) (Additional file 1 : Table S2) [31, 32]. The most common ADR classified by SOC was "Infections and infestations", which is consistent with findings in the above studies.

Some studies reported that infection was more frequent soon after the start of treatment with TNF inhibitors [33-35], and the same tendency was noted in the present study. However, infections were observed throughout the study period, indicating that attention should be paid to infections not only soon after treatment initiation but also thereafter.

Patients with comorbid respiratory disease or history of allergic disease had a significantly higher incidence of infections. In addition to these two factors, concomitant use of glucocorticoids was also identified as an independent factor associated with infection (Additional file 1: Table S1). Comorbid respiratory disease and concomitant glucocorticoid use were identified as risk factors for infection in Japanese PMS when using IFX and other biologic agents [36-38]. In addition, a history of allergic disease was reported as a risk factor for infections in a UK cohort study [39]. Patients with these risk factors warrant particular attention to risk of infections. Although age and concomitant cyclosporine use were not significantly correlated with infections in this study, advanced age and concomitant use of immunosuppressants are reported risk factors for serious infections in other diseases [36-38]. Patients with such risk factors therefore warrant more careful monitoring.

$\mathrm{TB}$, a major concern during treatment with TNF inhibitors [40, 41], was observed in only two patients $(0.30 \%)$ during the 24-month follow-up period. However, this occurrence is higher than that in the Japanese population (14.4/100,000 patient-years,) (http://www.mhlw.go.jp/ file/06-Seisakujouhou-10900000-Kenkoukyoku/00001338 22.pdf, Japanese article, last accessed December 25, 2018), despite $36.9 \%$ of patients receiving prophylactic anti-TB drugs. Careful attention therefore should be paid to TB during IFX treatment.

IRs were observed in $11.13 \%$ of patients; however, most were non-serious. After the occurrence of their first IR, most patients were re-treated with IFX; serious IRs were observed in approximately $3 \%$ of patients at re-infusion, whereas two thirds had no further IR (Additional file 1: Figure S1). Re-infusion therefore appears to be relatively safe in patients with a history of IRs.

In this study, IFX exhibited good efficacy as observed in a previous Japanese clinical trial [18], showing rapid 


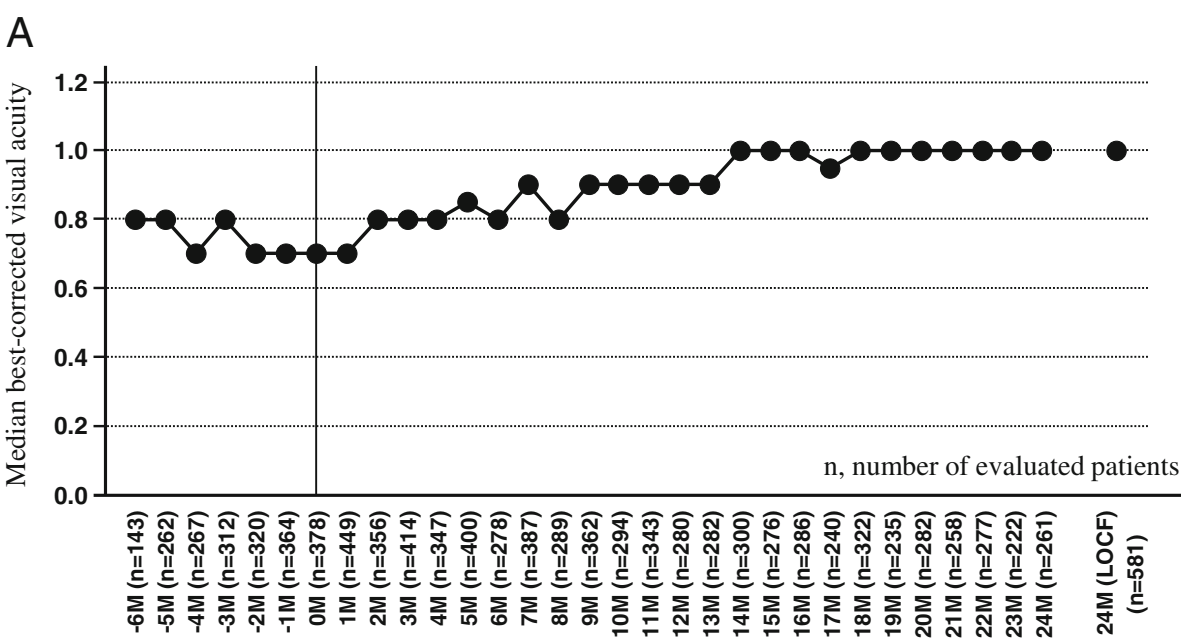

B
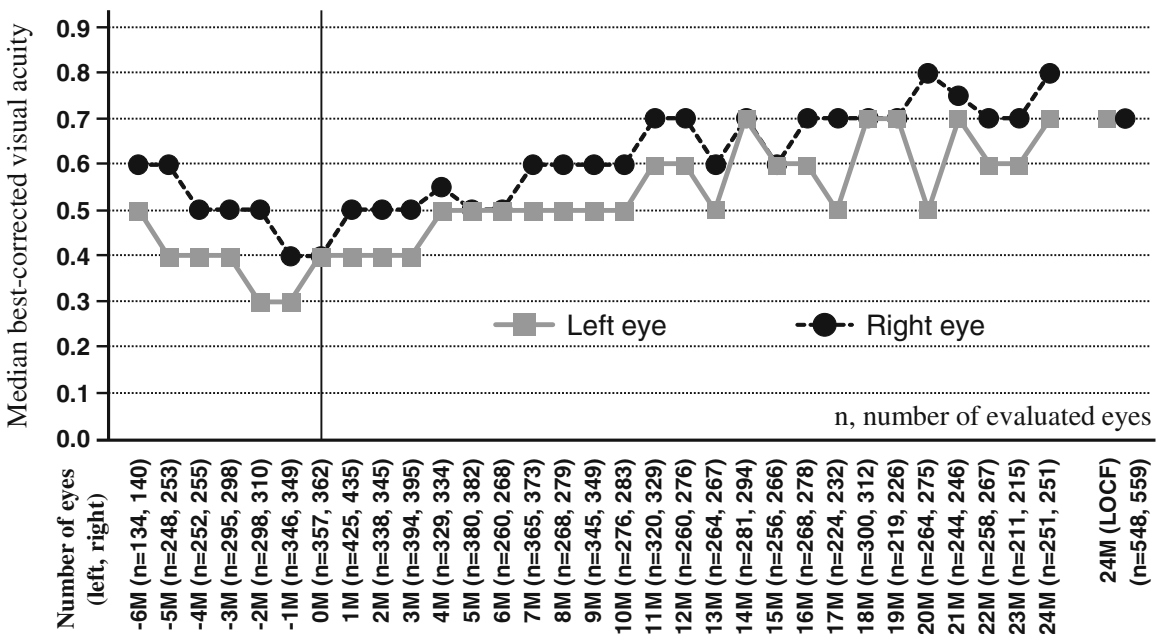

Fig. $\mathbf{2}$ Change in the best-corrected visual acuity per patient (defined as better corrected acuity at each time point per patient) (a), and per each eye (b). The corrected visual acuity was examined on a monthly basis. M months, LOCF last observation carried forward

Table 4 Percentage and dosage of concomitant drug use

\begin{tabular}{|c|c|c|c|c|c|}
\hline & $\begin{array}{l}\text { Day } 0 \\
(n=656)\end{array}$ & $\begin{array}{l}\text { Day } 180 \\
(n=624)\end{array}$ & $\begin{array}{l}\text { Day 365 } \\
(n=597)\end{array}$ & $\begin{array}{l}\text { Day } 545 \\
(n=565)\end{array}$ & $\begin{array}{l}\text { Day } 730 \\
(n=544)\end{array}$ \\
\hline \multicolumn{6}{|l|}{ Cyclosporine } \\
\hline$n$ (rate) & $178(27.1)$ & $121(19.4)$ & $112(18.8)$ & $103(18.2)$ & $99(18.2)$ \\
\hline dose, mg/day & $150.00(100.00,200.00)$ & $100.00(100.00,150.00)$ & $100.00(75.00,150.00)$ & $100.00(75.00,150.00)$ & $100.00(75.00,150.00)$ \\
\hline \multicolumn{6}{|c|}{ Oral glucocorticoids } \\
\hline$n$ (rate) & $154(23.5)$ & $109(17.5)$ & $100(16.8)$ & $95(16.8)$ & $89(16.4)$ \\
\hline dose, mg/day & $10.00(7.50,20.00)$ & $6.50(5.00,10.00)$ & $5.00(4.00,10.00)$ & $5.00(5.00,10.00)$ & $5.00(5.00,10.00)$ \\
\hline \multicolumn{6}{|l|}{ Colchicine } \\
\hline$n$ (rate) & $271(41.3)$ & $202(32.4)$ & $186(31.2)$ & $168(29.7)$ & $155(28.5)$ \\
\hline dose, mg/day & $1.00(1.00,1.00)$ & $1.00(0.50,1.00)$ & $1.00(0.50,1.00)$ & $1.00(0.50,1.00)$ & $1.00(0.50,1.00)$ \\
\hline
\end{tabular}

Data are number (percentage) or median (1st quartile, 3rd quartile) 
Table 5 Association between patient background and occurrence of infections, PGA response, and reduction in ocular attacks

\begin{tabular}{|c|c|c|c|c|c|c|c|c|c|}
\hline & \multicolumn{3}{|c|}{ Infections } & \multicolumn{3}{|c|}{ PGA response } & \multicolumn{3}{|c|}{ Reduction in ocular attacks } \\
\hline & $\overline{\text { All }}$ & Occurred & $p^{a}$ & $\bar{A} \|^{b}$ & Response rate ${ }^{c}$ & $p^{a}$ & $\bar{A} \|^{d}$ & Absence of ocular attacks ${ }^{\mathrm{e}}$ & $p^{a}$ \\
\hline & $n$ & $n(\%)$ & & $n$ & $n(\%)$ & & $n$ & $n(\%)$ & \\
\hline All patients & 656 & $78(11.89)$ & - & 623 & $503(80.7)$ & - & 506 & $217(42.9)$ & - \\
\hline \multicolumn{10}{|c|}{ Disease duration of $\mathrm{BD}$, years } \\
\hline$<5$ & 268 & $25(9.33)$ & 0.130 & 255 & $216(84.7)$ & 0.008 & 212 & $88(41.5)$ & 0.216 \\
\hline$\geq 5-<10$ & 159 & $17(10.69)$ & & 153 & $128(83.7)$ & & 129 & $62(48.1)$ & \\
\hline$\geq 10-<15$ & 95 & $17(17.89)$ & & 88 & $70(79.5)$ & & 73 & $24(32.9)$ & \\
\hline$\geq 15$ & 77 & $11(14.29)$ & & 74 & $50(67.6)$ & & 55 & $23(41.8)$ & \\
\hline unknown & 57 & $8(14.04)$ & & 53 & $39(73.6)$ & & 37 & $20(54.1)$ & \\
\hline \multicolumn{10}{|c|}{ Disease duration of uveitis, years } \\
\hline$<5$ & 294 & $28(9.52)$ & 0.080 & 274 & $234(85.4)$ & 0.030 & 234 & $99(42.3)$ & 0.011 \\
\hline$\geq 5-<10$ & 166 & $19(11.45)$ & & 162 & $132(81.5)$ & & 130 & $70(53.8)$ & \\
\hline$\geq 10-<15$ & 86 & $17(19.77)$ & & 82 & $66(80.5)$ & & 71 & $22(31.0)$ & \\
\hline$\geq 15$ & 60 & $7(11.67)$ & & 58 & $40(69.0)$ & & 41 & 15 (36.6) & \\
\hline unknown & 50 & $7(14.00)$ & & 47 & $31(66.0)$ & & 30 & $11(36.7)$ & \\
\hline \multicolumn{10}{|c|}{ Severity of ocular symptoms } \\
\hline severe & 408 & $53(12.99)$ & 0.342 & 390 & $326(83.6)$ & $<0.001$ & 332 & $125(37.7)$ & 0.007 \\
\hline moderate & 201 & $18(8.96)$ & & 193 & $157(81.3)$ & & 154 & $81(52.6)$ & \\
\hline mild & 36 & $4(11.11)$ & & 33 & $18(54.5)$ & & 14 & $7(50.0)$ & \\
\hline unknown & 11 & $3(27.27)$ & & 7 & $2(28.6)$ & & 6 & $4(66.7)$ & \\
\hline \multicolumn{10}{|c|}{ History of allergic disease } \\
\hline no & 618 & $69(11.17)$ & 0.034 & 586 & $472(80.5)$ & 0.830 & 480 & $206(42.9)$ & 1.000 \\
\hline yes & 38 & $9(23.68)$ & & 37 & $31(83.8)$ & & 26 & $11(42.3)$ & \\
\hline \multicolumn{10}{|c|}{ Extraocular symptoms of $\mathrm{BD}$} \\
\hline \multicolumn{10}{|c|}{ oral aphthous ulcers ${ }^{f}$} \\
\hline no & 117 & $11(9.40)$ & 0.432 & 112 & $81(72.3)$ & 0.016 & 82 & $34(41.5)$ & 0.808 \\
\hline yes & 534 & $66(12.36)$ & & 506 & $419(82.8)$ & & 421 & $182(43.2)$ & \\
\hline \multicolumn{10}{|l|}{ skin lesions $^{f}$} \\
\hline no & 259 & $30(11.58)$ & 0.902 & 245 & $186(75.9)$ & 0.012 & 197 & 76 (38.6) & 0.118 \\
\hline yes & 392 & $47(11.99)$ & & 373 & $314(84.2)$ & & 306 & $140(45.8)$ & \\
\hline \multicolumn{10}{|c|}{ central nervous system lesions ${ }^{f}$} \\
\hline no & 587 & 68 (11.58) & 0.542 & 559 & $463(82.8)$ & 0.001 & 460 & $197(42.8)$ & 0.873 \\
\hline
\end{tabular}

Extraocular symptoms of BD

oral aphthous ulcers ${ }^{\dagger}$

$\begin{array}{cccccccccc}\text { no } & 117 & 11(9.40) & 0.432 & 112 & 81(72.3) & 0.016 & 82 & 34(41.5) & 0.808 \\ \begin{array}{c}\text { yes } \\ \text { skin lesions }\end{array} & 534 & 66(12.36) & & 506 & 419(82.8) & & 421 & 182(43.2) & \\ \text { no } & 259 & 30(11.58) & 0.902 & 245 & 186(75.9) & 0.012 & 197 & 76(38.6) & 0.118 \\ \text { yes } & 392 & 47(11.99) & & 373 & 314(84.2) & & 306 & 140(45.8)\end{array}$

central nervous system lesions ${ }^{\mathrm{f}}$

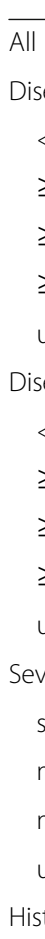

$\begin{array}{llllll}\text { no } & 587 & 68(11.58) & 0.542 & 559 & 463(82.8) \\ \text { yes } & 64 & 9(14.06) & & 59 & 37(62.7)\end{array}$

intestinal tract lesions ${ }^{\dagger}$

\begin{tabular}{|c|c|c|c|c|c|c|c|c|}
\hline no & 584 & $67(11.47)$ & 0.423 & 557 & $460(82.6)$ & 0.003 & 471 & $200(42.5)$ \\
\hline yes & 67 & $10(14.93)$ & & 61 & $40(65.6)$ & & 32 & $16(50.0)$ \\
\hline \multicolumn{9}{|c|}{ morbidity } \\
\hline \multicolumn{9}{|c|}{ respiratory disease } \\
\hline no & 646 & $74(11.46)$ & 0.022 & 614 & 497 (80.9) & 0.385 & 500 & $215(43.0)$ \\
\hline yes & 10 & $4(40.00)$ & & 9 & $6(66.7)$ & & 6 & $2(33.3)$ \\
\hline \multicolumn{9}{|c|}{ cardiac disease } \\
\hline no & 646 & $76(11.76)$ & 0.338 & 616 & $500(81.2)$ & 0.029 & 499 & $213(42.7)$ \\
\hline yes & 10 & $2(20.00)$ & & 7 & $3(42.9)$ & & 7 & $4(57.1)$ \\
\hline
\end{tabular}

diabetes mellitus 
Table 5 Association between patient background and occurrence of infections, PGA response, and reduction in ocular attacks (Continued)

\begin{tabular}{|c|c|c|c|c|c|c|c|c|c|}
\hline & \multicolumn{3}{|c|}{ Infections } & \multicolumn{3}{|c|}{ PGA response } & \multicolumn{3}{|c|}{ Reduction in ocular attacks } \\
\hline & $\overline{\text { All }}$ & Occurred & $p^{a}$ & $\overline{A l l}{ }^{b}$ & Response rate ${ }^{c}$ & $p^{\mathrm{a}}$ & $\overline{\mathrm{All}^{\mathrm{d}}}$ & Absence of ocular attacks ${ }^{\mathrm{e}}$ & $p^{\mathrm{a}}$ \\
\hline & $n$ & $n(\%)$ & & $n$ & $n(\%)$ & & $n$ & $n(\%)$ & \\
\hline no & 625 & $74(11.84)$ & 0.778 & 593 & $486(82.0)$ & 0.002 & 486 & $214(44.0)$ & 0.010 \\
\hline yes & 31 & $4(12.90)$ & & 30 & $17(56.7)$ & & 20 & $3(15.0)$ & \\
\hline Concomit & & & & & & & & & \\
\hline cyclosp & & & & & & & & & \\
\hline no & 443 & $48(10.84)$ & 0.247 & 418 & $338(80.9)$ & 0.914 & 332 & $158(47.6)$ & 0.003 \\
\hline yes & 213 & $30(14.08)$ & & 205 & $165(80.5)$ & & 174 & $59(33.9)$ & \\
\hline glucoc & & & & & & & & & \\
\hline no & 124 & $10(8.06)$ & 0.167 & 114 & $101(88.6)$ & 0.018 & 93 & $43(46.2)$ & 0.488 \\
\hline yes & 532 & $68(12.78)$ & & 509 & $402(79.0)$ & & 413 & $174(42.1)$ & \\
\hline
\end{tabular}

The association between the safety/efficacy and patient background factors (as described in Table 1) such as sex, age, and comorbidity were evaluated using univariate analysis. Results were shown in the patient background with significant $(p<0.05)$ association with occurrence of infections, physician global assessment (PGA) response, or reduction in ocular attacks

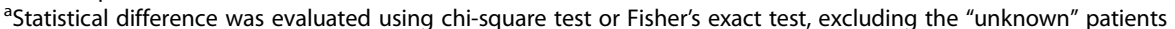

"Patients with available PGA data excluding "underminable"

${ }^{\mathrm{C}}$ Response was defined as improved or slightly improved

${ }^{d}$ Evaluated in 506 patients who showed at least one ocular attacks in prior 6 months and had no history of infliximab treatment

ePatients with absence of ocular attacks during the study period

${ }^{f} n=643$ (excluded the 5 patients without data on extraocular symptoms of Behçet's disease (BD))

and long-term PGA response, decreasing number of ocular attacks, and maintenance of visual acuity. In addition, the rates of cyclosporine, glucocorticoid, and colchicine use were also reduced after initiation of IFX treatment. ADRs related to cyclosporine such as renal dysfunction and central nervous system effects limit the therapeutic benefit of cyclosporine [42, 43]. IFX treatment enabled a reduction in the use of immunosuppressants, and therefore potentially reduced the risk of ADRs related to these agents.

We also identified patient background factors associated with efficacy (PGA responses and absence of ocular attacks). The incidence of ocular attacks following administration of IFX was lower in patients with severe ocular symptoms than in those with moderate/mild symptoms. Interestingly, however, the PGA response rate was conversely higher. PGA responses represent a subjective measure, and efficacy may have been evaluated higher in those patients with more severe ocular symptoms. In addition, some extraocular symptoms were identified as factors associated with PGA responses. The responsiveness of these symptoms to IFX treatment is also conjectured to have influenced the evaluation of PGA responses.

In this study, the number of ocular attacks during the 6 months just prior to IFX treatment was identified as independently negatively associated with the absence of ocular attacks following IFX treatment (odds ratio= 0.757, Additional file 1: Table S2). The annual number of ocular attacks and cumulative number of ocular attacks in RUBD patients have been reported to be associated with reductions in visual acuity [44, 45]. Visual acuity was maintained in patients with early introduction of IFX therapy [25]. The results of univariate analysis in the present study also showed that patients with a shorter duration of uveoretinitis had a significantly lower incidence of ocular attacks and greater improvement in PGA following administration of IFX. Taking these findings into account, early introduction of IFX therapy prior to severe progression of uveoretinitis is expected to lead to a reduction in ocular attacks and the maintenance of visual acuity.

IFX treatment has also been reported to have excellent efficacy in the treatment of several extraocular symptoms of BD [46-48]. In August 2015 the indication of IFX for intestinal, neurological, and vascular involvement in Behçet's disease was approved in Japan, based on the results of a phase III study [49]. PMS in these patients is now ongoing in Japan, and the results are expected to provide new insights into BD treatment with IFX.

\section{Conclusions}

The BRIGHT study, a prospective large-scale, long-term PMS study, has clarified the long-term safety and efficacy of and adherence to IFX treatment, and identified associated factors for safety and efficacy, in the treatment of RUBD patients in real-world clinical settings. The safety profile of IFX was similar to that observed in previous studies, and no new safety concerns were observed. In addition, the efficacy of IFX treatment was maintained for an extended period. These results suggest that IFX is a suitable treatment option for RUBD in real-world clinical settings. 


\section{Additional file}

Additional file 1: Figure S1. Re-infusion of IFX in patients with BD who developed IRs. Table S1. Independent factors associated with any infections and efficacy. Table S2. Safety profile of IFX therapy in patients with $B D, R A, C r o h n ' s$ disease (CD) or psoriasis (PsO) in the Japanese PMS study. (PDF $151 \mathrm{~kb})$

\section{Abbreviations}

ADRs: Adverse drug reactions; BD: Behçet's disease; Cl: Confidence interval; EAU: Experimental autoimmune uveoretinitis; GPSP: Good post-marketing surveillance practice; HBV: Hepatitis B virus; IFX: Infliximab; IR: Infusion reactions; LOCF: Last observation carried forward; MedDRA: Medical dictionary for regulatory activities; PGA: Physician global assessment; PMS: Postmarketing surveillance; Q1: First quartile; Q3: Third quartile; RUBD: Refractory uveoretinitis in Behçet's disease (RUBD); SOC: System organs class; TB: Tuberculosis; TNF: Tumor necrosis factor-alpha; TST: Tuberculin skin tests

\section{Acknowledgements}

The authors would like to take this opportunity to thank the investigators involved in this postmarketing surveillance study. The authors also thank J P Barron, Professor Emeritus of Tokyo Medical University, for his editorial review of this manuscript.

\section{Funding}

This work was supported by Mitsubishi Tanabe Pharma Corporation, Osaka, Japan, which was responsible for the collection and analysis of data.

\section{Availability of data and materials}

The datasets generated and/or analyzed during the current study are not publicly available due to not obtaining the consent for permission to publicly share their data from investigators involved in this study, but are available from the corresponding author on reasonable request.

\section{Authors' contributions}

All authors were involved in the study design and interpretation of data. SO participated in the study as an investigator, and was involved in writing this manuscript. UI, MM, and TG analyzed the data. TY carried out the literature search, and prepared the draft manuscript. All authors had full access to all data in the study, and read and approved the final manuscript.

\section{Ethics approval and consent to participate}

This PMS study protocol was approved by the Ministry of Health, Labor and Welfare of the Japan Government, and was conducted in accordance with good post-marketing surveillance practice (GPSP), which sets the standard for PMS studies of approved drugs in clinical practice. Patients were treated in accordance with physicians' usual clinical practice and indication for commercially available IFX.; no consent was needed by the institutions' ethics committees.

\section{Consent for publication}

Not applicable.

\section{Competing interests}

SO has received expert testimony fees from Mitsubishi Tanabe Pharma Corporation, AbbVie GK, Alcon Japan, Bosch \& Lomb Japan, and Santen Pharmaceutical Company; grants/research support from Mitsubishi Tanabe Pharma Corporation; lecture fees from Mitsubishi Tanabe Pharma Corporation, Alcon Japan, Otsuka Pharmaceutical Company, and Santen Pharmaceutical Company; patent fees from Mitsubishi Tanabe Pharma Corporation. IU, MM, TG, and TY are full-time employees of Mitsubishi Tanabe Pharma Corporation.

\section{Publisher's Note}

Springer Nature remains neutral with regard to jurisdictional claims in published maps and institutional affiliations.

\section{Author details}

${ }^{1}$ Department of Ophthalmology, Faculty of Medicine and Graduate School of Medicine, Hokkaido University, N 15, W 7, Kita-ku, Sapporo, Hokkaido 060-8638, Japan. ${ }^{2}$ Department of Ophthalmology, Aishin Memorial Hospital, 1-15, N27, E1, Higashi-ku, Sapporo, Hokkaido 065-0027, Japan. ${ }^{3}$ Ikuyaku. Integrated Value Development Division, Mitsubishi Tanabe Pharma Corporation, 3-16-89, Kashima, Yodogawa-ku, Osaka, Japan. ${ }^{4}$ Ikuyaku. Integrated Value Development Division, Mitsubishi Tanabe Pharma Corporation, 3-2-10, Dosho-machi, Chuo-ku, Osaka, Japan.

Received: 31 July 2018 Accepted: 11 December 2018 Published online: 05 January 2019

References

1. Michelson JB, Chisari FV. Behçet's disease. Surv Ophthalmol. 1982;26:190203.

2. Jabs DA, Rosenbaum JT, Foster CS, Holland GN, Jaffe GJ, Louie JS, et al. Guidelines for the use of immunosuppressive drugs in patients with ocular inflammatory disorders: recommendations of an expert panel. Am J Ophthalmol. 2000;130:492-513.

3. Nakamura S, Yamakawa T, Sugita M, Kijima M, Ishioka M, Tanaka S, et al. The role of tumor necrosis factor-alpha in the induction of experimental autoimmune uveoretinitis in mice. Invest Ophthalmol Vis Sci. 1994;35:3884-9.

4. Sartani G, Silver PB, Rizzo LV, Chan CC, Wiggert B, Mastorakos G, et al. Antitumor necrosis factor alpha therapy suppresses the induction of experimental autoimmune uveoretinitis in mice by inhibiting antigen priming. Invest Ophthalmol Vis Sci. 1996;37:2211-8.

5. Nakamura S, Sugita M, Tanaka S, Ohno S. Enhanced production of in vitro tumor necrosis factor-alpha from monocytes in Behçet's disease. Nippon Ganka Gakkai Zasshi. 1992;96:1282-5.

6. Siegel SA, Shealy DJ, Nakada MT, Le J, Woulfe DS, Probert L, et al. The mouse/human chimeric monoclonal antibody CA2 neutralizes TNF in vitro and protects transgenic mice from cachexia and TNF lethality in vivo. Cytokine. 1995;7:15-25.

7. Scallon BJ, Moore MA, Trinh H, Knight DM, Ghrayeb JJ. Chimeric anti-TNFalpha monoclonal antibody CA2 binds recombinant transmembrane TNFalpha and activates immune effector functions. Cytokine. 1995;7:251-9.

8. Maini R, St Clair EW, Breedveld F, Furst D, Kalden J, Weisman M, et al. Infliximab (chimeric anti-tumour necrosis factor alpha monoclonal antibody) versus placebo in rheumatoid arthritis patients receiving concomitant methotrexate: a randomised phase III trial. ATTRACT Study Group. Lancet. 1999;354:1932-9.

9. Hanauer SB, Feagan BG, Lichtenstein GR, Mayer LF, Schreiber S, Colombel $J$, et al. Maintenance infliximab for Crohn's disease: the ACCENT I randomised trial. Lancet. 2002:359:1541-9.

10. Gottlieb AB, Evans R, Li S, Dooley LT, Guzzo CA, Baker D, et al. Infliximab induction therapy for patients with severe plaque-type psoriasis: a randomized, double-blind, placebo-controlled trial. J Am Acad Dermatol. 2004;51:534-42.

11. van der Heijde D, Dijkmans B, Geusens P, Sieper J, DeWoody K, Williamson $P$, et al. Efficacy and safety of infliximab in patients with ankylosing spondylitis: results of a randomized, placebo-controlled trial (ASSERT). Arthritis Rheum. 2005;52:582-91.

12. Antoni CE, Kavanaugh A, Kirkham B, Tutuncu Z, Burmester GR, Schneider U, et al. Sustained benefits of infliximab therapy for dermatologic and articular manifestations of psoriatic arthritis: results from the infliximab multinational psoriatic arthritis controlled trial (IMPACT). Arthritis Rheum. 2005;52:1227-36.

13. Rutgeerts P, Sandborn WJ, Feagan BG, Reinisch W, Olson A, Johanns J, et al. Infliximab for induction and maintenance therapy for ulcerative colitis. $\mathrm{N}$ Engl J Med. 2005;353:2462-76.

14. Mori M, Hara T, Kikuchi M, Shimizu H, Miyamoto T, Iwashima S, et al. Infliximab versus intravenous immunoglobulin for refractory Kawasaki disease: a phase 3, randomized, open-label, active-controlled, parallel-group, multicenter trial. Sci Rep. 2018;8:1994.

15. Atzeni F, Doria A, Carrabba M, Turiel M, Sarzi-Puttini P. Potential target of infliximab in autoimmune and inflammatory diseases. Autoimmun Rev. 2007:6:529-36.

16. Sfikakis PP, Theodossiadis PG, Katsiari CG, Kaklamanis P, Markomichelakis NN Effect of infliximab on sight-threatening panuveitis in Behçet's disease. Lancet. 2001;358:295-6. 
17. Cantini F, Niccoli L, Nannini C, Kaloudi O, Cassarà E, Susini M, et al. Efficacy of infliximab in refractory Behçet's disease-associated and idiopathic posterior segment uveitis: a prospective, follow-up study of 50 patients. Biologics. 2012;6:5-12.

18. Ohno S, Nakamura S, Hori S, Shimakawa M, Kawashima H, Mochizuki M, et al. Efficacy, safety, and pharmacokinetics of multiple administration of infliximab in Behçet's disease with refractory uveoretinitis. J Rheumatol. 2004;31:1362-8.

19. Namba K, Goto H, Kaburaki T, Kitaichi N, Mizuki N, Asukata Y, et al. A Major Review: current aspects of ocular Behçet's disease in Japan. Ocul Immunol Inflamm. 2015;23(Suppl 1):S1-23.

20. Committee for the Preparation of Clinical Treatment of Ocular Lesions Related to Behcet's Disease. Guidelines for the clinical management of ocular Behçet's disease. Nippon Ganka Gakkai Zasshi. 2012;116:394-426.

21. Yamada Y, Sugita S, Tanaka H, Kamoi K, Kawaguchi T, Mochizuki M. Comparison of infliximab versus ciclosporin during the initial 6-month treatment period in Behçet disease. Br J Ophthalmol. 2010;94:284-8.

22. Tanaka H, Sugita S, Yamada Y, Kawaguchi T, Iwanaga Y, Kamoi K, et al. Effects and safety of infliximab administration in refractory uveoretinitis with Behçet's disease. Nippon Ganka Gakkai Zasshi. 2010;114:87-95.

23. Okada AA, Goto H, Ohno S, Mochizuki M. Multicenter study of infliximab for refractory uveoretinitis in Behçet disease. Arch Ophthalmol. 2012;130:592-8.

24. Takeuchi M, Kezuka T, Sugita S, Keino H, Namba K, Kaburaki T, et al. Evaluation of the long-term efficacy and safety of infliximab treatment for uveitis in Behçet's disease: a multicenter study. Ophthalmology. 2014;121: 1877-84.

25. Keino H, Okada AA, Watanabe T, Nakayama M, Nakamura T. Efficacy of infliximab for early remission induction in refractory uveoretinitis associated with Behçet disease: a 2-year follow-up study. Ocul Immunol Inflamm. 2017; 25:46-51.

26. Al-Rayes H, Al-Swailem R, Al-Balawi M, Al-Dohayan N, Al-Zaidi S, Tariq M. Safety and efficacy of infliximab therapy in active Behcet's uveitis: an openlabel trial. Rheumatol Int. 2008;29:53-7.

27. Niccoli L, Nannini C, Benucci M, Chindamo D, Cassarà E, Salvarani C, et al. Long-term efficacy of infliximab in refractory posterior uveitis of Behçet's disease: a 24-month follow-up study. Rheumatology (Oxford). 2007:46:1161-4.

28. Tugal-Tutkun I, Mudun A, Urgancioglu M, Kamali S, Kasapoglu E, Inanc M, et al. Efficacy of infliximab in the treatment of uveitis that is resistant to treatment with the combination of azathioprine, cyclosporine, and corticosteroids in Behçet's disease: an open-label trial. Arthritis Rheum. 2005; 52:2478-84.

29. Calvo-Río V, Blanco R, Beltrán E, Sánchez-Bursón J, Mesquida M, Adán A, et al. Anti-TNF-a therapy in patients with refractory uveitis due to Behçet's disease: a 1-year follow-up study of 124 patients. Rheumatology (Oxford). 2014:53:2223-31.

30. Vallet $H$, Seve P, Biard L, Baptiste Fraison JB, Bielefeld P, Perard L, et al. Infliximab versus adalimumab in the treatment of refractory inflammatory uveitis: a multicenter study from the French Uveitis Network. Arthritis Rheumatol. 2016;68:1522-30.

31. Takeuchi T, Tatsuki Y, Nogami Y, Ishiguro N, Tanaka Y, Yamanaka H, et al. Postmarketing surveillance of the safety profile of infliximab in 5000 Japanese patients with rheumatoid arthritis. Ann Rheum Dis. 2008;67: 189-94.

32. Torii H, Terui T, Matsukawa M, Takesaki K, Ohtsuki M, Nakagawa $H$, et al. Safety profiles and efficacy of infliximab therapy in Japanese patients with plaque psoriasis with or without psoriatic arthritis, pustular psoriasis or psoriatic erythroderma: results from the prospective post-marketing surveillance. J Dermatol. 2016:43:767-78.

33. Delabaye I, De Keyser F. REMITRACT study group. 74-week follow-up of safety of infliximab in patients with refractory rheumatoid arthritis. Arthritis Res Ther. 2010;12:R121

34. Galloway JB, Hyrich KL, Mercer LK, Dixon WG, Fu B, Ustianowski AP, et al. Anti-TNF therapy is associated with an increased risk of serious infections in patients with rheumatoid arthritis especially in the first 6 months of treatment: updated results from the British Society for Rheumatology Biologics Register with special emphasis on risks in the elderly. Rheumatology (Oxford). 2011;50:124-31.

35. Sakai $R$, Komano $Y$, Tanaka M, Nanki $T$, Koike $R$, Nagasawa $H$, et al. Timedependent increased risk for serious infection from continuous use of tumor necrosis factor antagonists over three years in patients with rheumatoid arthritis. Arthritis Care Res (Hoboken). 2012;64:1125-34.
36. Takeuchi T, Tatsuki T, Murakami S, Nogami Y, Koike T. Serious infectious diseases associated with infliximab treatment in 5,000 Japanese rheumatoid arthritis patients followed prospectively in the post-marketing surveillance study (PMS). Ann Rheum Dis. 2007;66(suppl II):189.

37. Koike T, Harigai M, Inokuma S, Ishiguro N, Ryu J, Takeuchi T, et al. Postmarketing surveillance of safety and effectiveness of etanercept in Japanese patients with rheumatoid arthritis. Mod Rheumatol. 2011;21: 343-51.

38. Koike T, Harigai M, Ishiguro N, Inokuma S, Takei S, Takeuchi T, et al. Safety and effectiveness of adalimumab in Japanese rheumatoid arthritis patients: postmarketing surveillance report of 7740 patients. Mod Rheumatol. 2014; 24:390-8.

39. Langan SM, Abuabara K, Henrickson SE, Hoffstad O, Margolis DJ. Increased risk of cutaneous and systemic infections in atopic dermatitis-a cohort study. J Invest Dermatol. 2017:137:1375-7.

40. Keane J, Gershon S, Wise RP, Mirabile-Levens E, Kasznica J, Schwieterman WD, et al. Tuberculosis associated with infliximab, a tumor necrosis factor alpha-neutralizing agent. N Engl J Med. 2001;345:1098-104.

41. Winthrop KL. Risk and prevention of tuberculosis and other serious opportunistic infections associated with the inhibition of tumor necrosis factor. Nat Clin Pract Rheumatol. 2006;2:602-10.

42. Saricaoglu H, Bulbul EB, Cikman ST, Dilek K, Tunali S. Effects of long-term cyclosporine A therapy on renal functions in Behçet's disease. Int J Tissue React. 2004;26:93-6.

43. Kotake S, Higashi K, Yoshikawa K, Sasamoto Y, Okamoto T, Matsuda H. Central nervous system symptoms in patients with Behçet disease receiving cyclosporine therapy. Ophthalmology. 1999;106:586-9.

44. Takeuchi M, Hokama H, Tsukahara R, Kezuka T, Goto H, Sakai J, et al. Risk and prognostic factors of poor visual outcome in Behcet's disease with ocular involvement. Graefes Arch Clin Exp Ophthalmol. 2005;243:1147-52.

45. Kaburaki T, Araki F, Takamoto M, et al. Best-corrected visual acuity and frequency of ocular attacks during the initial 10 years in patients with Behçet's disease. Graefes Arch Clin Exp Ophthalmol. 2010;248:709-14.

46. Fujikawa K, Aratake K, Kawakami A, et al. Successful treatment of refractory neuro-Behçet's disease with infliximab: a case report to show its efficacy by magnetic resonance imaging, profile transcranial magnetic stimulation and cytokine. Ann Rheum Dis. 2007;66:136-7.

47. Naganuma M, Sakuraba A, Hisamatsu T, et al. Efficacy of infliximab for induction and maintenance of remission in intestinal Behçet's disease. Inflamm Bowel Dis. 2008;14:1259-64.

48. Haugeberg G, Velken M, Johnsen V. Successful treatment of genital ulcers with infliximab in Behçet's disease. Ann Rheum Dis. 2004;63:744-5.

49. Hibi T, Hirohata S, Kikuchi H, Tateishi U, Sato N, Ozaki K, et al. Infliximab therapy for intestinal, neurological, and vascular involvement in Behcet disease: efficacy, safety, and pharmacokinetics in a multicenter, prospective, open-label, single-arm phase 3 study. Medicine (Baltimore). 2016;95:e3863.

\section{Ready to submit your research? Choose BMC and benefit from:}

- fast, convenient online submission

- thorough peer review by experienced researchers in your field

- rapid publication on acceptance

- support for research data, including large and complex data types

- gold Open Access which fosters wider collaboration and increased citations

- maximum visibility for your research: over $100 \mathrm{M}$ website views per year

At BMC, research is always in progress.

Learn more biomedcentral.com/submissions 